\title{
Chromosomal Q-Heterochromatin and Age in Human Population
}

\author{
Ibraimov A. I. ${ }^{1,2}$, Akanov A. A. ${ }^{1}$, Baygazieva G. D. ${ }^{1} \&$ Meimanaliev T. S. ${ }^{1}$ \\ ${ }^{1}$ Kazakh National Medical University after name S. D. Asfendyarov, Almaty, Kazakhstan \\ ${ }^{2}$ Laboratory of Human Genetics, National Center of Cardiology and Internal Medicine, Bishkek, Kyrgyzstan \\ Correspondence: Ibraimov A. I., Laboratory of Human Genetics, National Center of Cardiology and Internal \\ Medicine, Bishkek, Kyrgyzstan. E-mail: ibraimov_abyt@mail.ru
}

Received: January 27, 2014 Accepted: March 2, 2014 Online Published: March 21, 2014

doi:10.5539/jmbr.v4n1p1 URL: http://dx.doi.org/10.5539/jmbr.v4n1p1

\begin{abstract}
Individuals in the population differ from each other in number, location, size and intensity of fluorescence of chromosomal Q-heterochromatin regions (Q-HRs). It has been shown that human populations differ significantly as concerns this feature. The question remains open as to whether there exist differences between individuals belonging to different age groups. This fact is very important for understanding the possible biological role of the broad quantitative variability of chromosomal Q-HRs in human genome. The quantitative content of chromosomal Q-HRs was studied in individuals of Kazakh and Russian nationality from different age groups. It was shown that chromosomal Q-HRs are most numerous in the genome of neonates, while they are the least numerous in the genome of elderly subjects (aged 60 years and older). It is supposed that the lesser amount of Q-HRs in the genome of elderly subjects is due to the selective advantage in their survival to old age. The possible selective value of chromosomal Q-HRs is discussed.
\end{abstract}

Keywords: chromosomal Q-heterochromatin, Q-heterochromatin polymorphism, Q-heterochromatin selection, age groups, human adaptation

\section{Introduction}

A fundamental feature of chromosomes of higher eukaryotes, including man, is the presence of two evolutionary consolidated types of genetic material: euchromatin and heterochromatin. Euchromatin - the conservative portion of the genome - contains transcribed structural genes, while heterochromatin - the variable portion of the genome - predominantly consists of nontranscribed repeated DNA sequences.

Heterochromatin is universally distributed in the chromosomes of all the higher eukaryotes, amounting to $10 \%$ $60 \%$ of their genome. About $15 \%-20 \%$ of the human genome is composed of heterochromatin regions (HRs) (John, 1988). Chromosomal HRs does not change during ontogenesis and are clearly inherited as discrete features.

To-date, two types of heterochromatin are known: C- and Q-heterochromatin. There are several significant differences between them, including the fact that C-heterochromatin is encountered in chromosomes of all higher eukaryotes, while Q-heterochromatin is only present in man, the chimpanzee and gorilla. In man C-heterochromatin is present in all his chromosomes, varying mainly in size, while Q-heterochromatin can only be detected on seven autosomes and the Y-chromosome (Paris Conference, 1971, 1975).

Individuals in a population differ from each other in the number, location, size and intensity of staining (fluorescence) of chromosomal Q-heterochromatin regions (Q-HRs). It has been shown that certain human populations differ significantly as concerns this feature (Geraedts \& Pearson, 1974; Müller et al., 1975; Buckton et al., 1976; Lubs et al., 1977; Yamada \& Hasegawa, 1978; Al-Nassar, 1981; Ibraimov \& Mirrakhimov, 1982a, 1982b, 1982c; Ibraimov et al., 1982, 1986, 1990, 1991, 2000, 2013; Stanyon et al., 1988; Kalz et al., 2005; Decsey et al., 2006). The question remains open as to whether there exist differences between individuals belonging to different age groups in population. This fact is very important for understanding the possible biological role of the broad quantitative variability of human chromosomal Q-HRs.

\section{Materials and Methods}

\subsection{Sample Characteristics}

Using identical methods we studied neonates, as well as students from Kazakh National Medical University in 
Almaty. The group of elderly subjects (aged 60 years and over) consisted of individuals living in the Old People's Homes of Almaty. In the studied samples only individuals whose parents were from the same ethnic group are included.

\subsection{Cytogenetic Methods}

Chromosomal preparations were made using short-term cultures of peripheral blood lymphocytes, with the exception of newborn infants where umbilical blood was used. The cell cultures were processed according to slightly modified (Ibraimov, 1983a) conventional methods (Hungerford, 1965). The dye used was quinacrine mustard. All the chromosomal preparations were analyzed by one and the same cytogeneticist (A.I.I.) to investigate chromosomal Q-HR variability. Calculation and registration of chromosomal Q-HRs was performed using the criteria and methods described in detail elsewhere (Ibraimov et al., 1982, 1990).

\subsection{Quantitative Characteristics of Q-HR Variability and Methods Used for Comparisons}

Q-HR variability of autosomes in populations is usually described in the form of three main quantitative characteristics:

1) The distribution of the number of Q-HRs in a population, i.e., distribution of individuals having different numbers of Q-HRs in the karyotype regardless of their location on seven Q-polymorphic autosomes, which also reflected the range of Q-HRs variability in the population genome;

2) The derivative of this distribution, an important population characteristic, is the mean number of Q-HRs per individual;

3) The frequency of Q-HRs on seven Q-polymorphic autosomes (3, 4, 13-15, 21 and 22) in the population. Despite the fact that in human autosomes there are twelve loci in which Q-HRs can be detected ( 3 cen, 4 cen, 13 p11, 13 p13, 14 p11, 14 p13, 15 p11, 15 p13, 21 p11, 21 p13, 22 p11, 22 p13), individuals with 24 Q-HRs in their genome could exist, but such cases have not as yet been reported. In individuals of a population the number of Q-HRs on the autosomes usually ranges from zero to ten (Yamada \& Hasegawa, 1978; Al-Nassar et al., 1981; Ibraimov \& Mirrakhimov, 1985; Ibraimov, 2010).

The distribution of the numbers and mean number of Q-HR per individual in samples were compared using the Student $t$-test.

\section{Results}

Table 1 and Table 2 show the distribution of the numbers and mean number of Q-HRs on autosomes in studied age groups of Kazakh and Russian nationality. As can be seen from these Tables, in every case neonates are characterized by the highest mean number value, and by a broad range of variability in the distribution of Q-HRs as compared to individuals from older groups and especially from groups of elderly subjects. 
Table 1. Distribution of the numbers and mean number of chromosomal Q-HRs per individual in Kazakh samples

\begin{tabular}{|c|c|c|c|}
\hline Number of Q-HRs & $\begin{array}{c}\text { Newborns } \\
(\mathrm{n}=389) \\
\mathrm{I}\end{array}$ & $\begin{array}{c}18-25 \text { years } \\
(\mathrm{n}=239) \\
\text { II }\end{array}$ & $\begin{array}{c}60 \text { years and older } \\
(\mathrm{n}=33) \\
\text { III }\end{array}$ \\
\hline 0 & $4(1.0 \%)$ & & $2(6.0 \%)$ \\
\hline 1 & $9(2.3 \%)$ & $16(6.7 \%)$ & $5(15.1 \%)$ \\
\hline 2 & $60(15.4 \%)$ & $36(15.1 \%)$ & $7(21.2 \%)$ \\
\hline 3 & $85(21.9 \%)$ & $58(24.3 \%)$ & $12(36.4 \%)$ \\
\hline 4 & $97(24.9 \%)$ & $60(25.1 \%)$ & $6(18.2 \%)$ \\
\hline 5 & $76(19.5 \%)$ & $44(18.4 \%)$ & $1(3.0 \%)$ \\
\hline 6 & $38(9.8 \%)$ & $17(7.1 \%)$ & \\
\hline 7 & $20(5.1 \%)$ & $7(2.9 \%)$ & \\
\hline 8 & & $1(0.4 \%)$ & \\
\hline Total & $1520(99.9 \%)$ & $881(100.0 \%)$ & $84(99.9 \%)$ \\
\hline Mean number of Q-HRs & $3.91 \pm 0.07$ & $3.69 \pm 0.09$ & $2.55 \pm 0.213$ \\
\hline Statistics & $\begin{array}{l}\mathrm{t}_{\mathrm{I}, \mathrm{II}}=1.808 ; \\
\mathrm{t}_{\mathrm{I}, \mathrm{III}}=5.068 ; \\
\mathrm{t}_{\mathrm{II}, \mathrm{III}}=4.259 ;\end{array}$ & $\begin{array}{l}\mathrm{df}=626 \\
\mathrm{df}=420 \\
\mathrm{df}=270\end{array}$ & $\begin{array}{l}\mathrm{P}=0.071 ; \\
\mathrm{P}=<0.001 ; * \\
\mathrm{P}=<0.001 ; *\end{array}$ \\
\hline
\end{tabular}

* - these differences are statistically significant.

Table 2. Distribution of the numbers and mean number of chromosomal Q-HRs per individual in Russian samples

\begin{tabular}{cccc}
\hline Number of Q-HRs & $\begin{array}{c}\text { Newborns } \\
(\mathrm{n}=83)\end{array}$ & $\begin{array}{c}18-25 \text { years } \\
(\mathrm{n}=60)\end{array}$ & $\begin{array}{c}60 \text { years and older } \\
(\mathrm{n}=80)\end{array}$ \\
\hline 0 & $1(1.2 \%)$ & $\mathrm{II}$ & $4(5.0 \%)$ \\
1 & $4(4.8 \%)$ & $4(6.6 \%)$ & $6(7.5 \%)$ \\
2 & $9(10.8 \%)$ & $7(11.7 \%)$ & $28(35.0 \%)$ \\
3 & $14(16.9 \%)$ & $14(23.3 \%)$ & $23(28.7 \%)$ \\
4 & $30(36.1 \%)$ & $17(28.3 \%)$ & $14(17.5 \%)$ \\
5 & $16(19.3 \%)$ & $13(21.6 \%)$ & $5(6.2 \%)$ \\
6 & $6(7.2 \%)$ & $4(6.6 \%)$ & \\
7 & $3(3.6 \%)$ & $1(1.6 \%)$ & \\
Total & $321(99.9 \%)$ & $224(99.9 \%)$ & $212(99.9 \%)$ \\
\hline Mean number of Q-HRs & $3.87 \pm 0.156$ & $3.73 \pm 0.177$ & $2.65 \pm 0.133$ \\
\hline & $\mathrm{t}_{\mathrm{I}, \mathrm{II}}=0.502 ;$ & $\mathrm{df}=141 ;$ & $\mathrm{P}=0.575$ \\
Statistics & $\mathrm{t}_{\mathrm{I}, \mathrm{III}}=5.895 ;$ & $\mathrm{df}=161 ;$ & $\mathrm{P}=<0.001 *$ \\
& $\mathrm{t}_{\mathrm{II}, \mathrm{III}}=4.980 ;$ & $\mathrm{df}=138 ;$ & $\mathrm{P}=<0.001 *$ \\
\hline
\end{tabular}

* - these differences are statistically significant.

As seen in Tables 1 and 2, there are no statistically significant differences between newborns and samples of young adults of the same nationality (18-25 - years old). However, a closer analysis showed that, in fact, these 
two age groups significantly differ from each other. It turned out that the main reason for the lack of differences between the two age groups was combining individuals of both sexes into one group. It has long been noted that at the population level, due to the largest block of Q-heterochromatin on Y chromosome in males, amount of Q-HRs on autosomes is less than in females (Ibraimov et al., 2000). When we compared newborns and students based on their gender, we found that these two age groups were significantly different from each other (Table 3).

Table 3 shows the distribution of the numbers and mean number of Q-HRs on autosomes in males and females in two age groups of Kazakh nationality. As can be seen from these Tables, in every case females are characterized by the highest mean number value, and by a broad range of variability in the distribution of the numbers of chromosomal Q-HRs as compared to males. These differences are statistically significant. Such regularities as in Kazakhs was also found in Russian samples (data not shown).

Table 3. Distribution of the numbers and mean number of Q-HRs on autosomes in males and females in newborn and 18 - 25 years individuals of Kazakh nationality

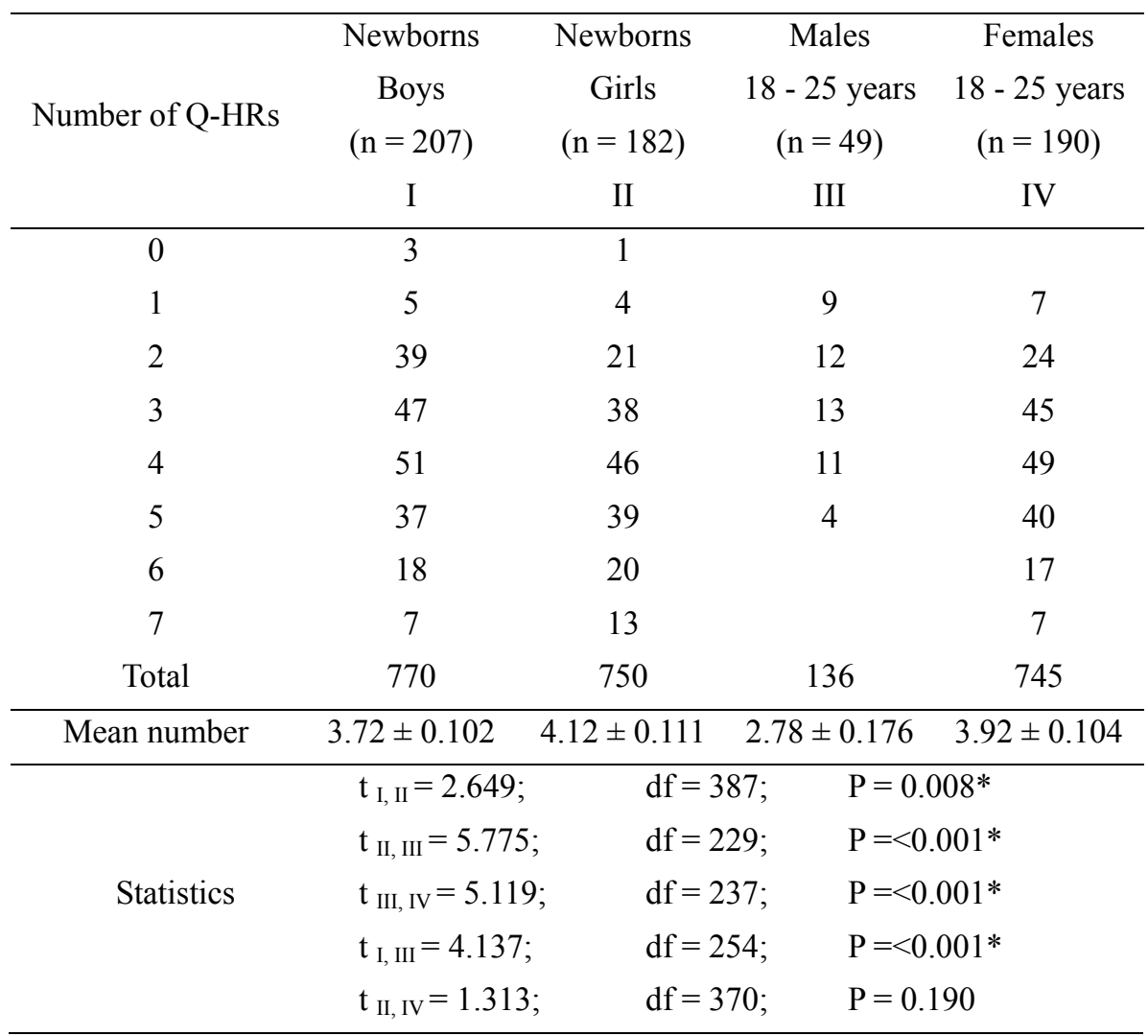

* - these differences are statistically significant.

Results of the comparative analyses of the frequency of Q-HRs on autosomes in individuals from different age groups are presented in Table 4. As it can be seen from this Table, a tendency is noted towards a decrease in the absolute frequency of Q-HRs with age in all the chromosomes. Of interest is the fact that this difference was pronounced in chromosome 3 and 13 containing more than half the Q-HRs of the human population genome. At the same time, individuals from all the age groups did not differ significantly from each other in the portion of Q-HRs in seven Q-polymorphic autosomes, in keeping with our previous observations (Ibraimov, 1993, 2010; Ibraimov et al., 1986, 1990, 1991, 2000, 2013). 
Table 4. Q-HRs frequencies in seven Q-polymorphic autosomes of Kazakh and Russian samples

\begin{tabular}{|c|c|c|c|c|c|c|}
\hline \multirow[b]{2}{*}{$\begin{array}{c}\text { Location of } \\
\text { Q-HRs }\end{array}$} & \multicolumn{3}{|c|}{ Kazakhs } & \multicolumn{3}{|c|}{ Russians } \\
\hline & $\begin{array}{l}\text { Newborns } \\
(\mathrm{n}=389)\end{array}$ & $\begin{array}{c}18-25 \text { years } \\
(\mathrm{n}=239)\end{array}$ & $\begin{array}{l}60 \text { years } \\
\text { and older } \\
(\mathrm{n}=33)\end{array}$ & $\begin{array}{c}\text { Newborns } \\
(\mathrm{n}=83)\end{array}$ & $\begin{array}{c}18-25 \text { years } \\
(n=60)\end{array}$ & $\begin{array}{c}60 \text { years and } \\
\text { older } \\
(\mathrm{n}=80)\end{array}$ \\
\hline \multirow{2}{*}{3} & $369(47.4)^{*}$ & $213(44.5)$ & $21(31.8)$ & $98(59.0)$ & $71(59.2)$ & $68(42.5)$ \\
\hline & $24.3 * *$ & 24.2 & 25.0 & 30.5 & 31.9 & 32.1 \\
\hline \multirow{2}{*}{4} & $74(9.5)$ & $48(10.0)$ & $3(4.5)$ & $10(6.0)$ & $8(6.7)$ & $5(3.1)$ \\
\hline & 4.9 & 5.4 & 3.5 & 3.1 & 3.7 & 2.4 \\
\hline \multirow{2}{*}{13} & $480(61.7)$ & $268(56.1)$ & $26(39.4)$ & $104(62.5)$ & $72(60.0)$ & $73(45.6)$ \\
\hline & 31.6 & 30.4 & 30.7 & 32.4 & 31.5 & 34.4 \\
\hline \multirow{2}{*}{14} & $117(15.0)$ & $68(14.2)$ & $8(12.1)$ & $25(15.0)$ & $17(14.1)$ & 17 (10.6) \\
\hline & 7.7 & 7.7 & 9.3 & 7.8 & 7.4 & 8.0 \\
\hline \multirow{2}{*}{15} & $161(20.7)$ & $77(16.1)$ & $9(13.6)$ & 33 (19.9) & $22(18.3)$ & $22(13.7)$ \\
\hline & 10.6 & 8.7 & 10.3 & 10.3 & 10.0 & 10.4 \\
\hline \multirow{2}{*}{21} & $196(25.2)$ & $108(22.6)$ & $10(15.1)$ & $30(18.1)$ & $16(13.3)$ & $18(11.2)$ \\
\hline & 12.9 & 12.3 & 12.4 & 9.3 & 7.3 & 8.5 \\
\hline \multirow{2}{*}{22} & $123(15.8)$ & $99(20.7)$ & $7(10.6)$ & $21(12.6)$ & $18(15.0)$ & $9(5.6)$ \\
\hline & 8.0 & 11.2 & 8.8 & 6.5 & 8.2 & 4.2 \\
\hline \multirow{2}{*}{ Всего } & $1520(195.4)$ & $881(184.3)$ & 84 (126.6) & $321(193.4)$ & $224(186.6)$ & $212(132.3)$ \\
\hline & 100.0 & 99.9 & 100.0 & 99.9 & 100.0 & 100.0 \\
\hline $\begin{array}{c}\text { Mean number } \\
\text { of Q-HRs }\end{array}$ & 3.91 & 3.69 & 2.55 & 3.86 & 3.16 & 2.65 \\
\hline
\end{tabular}

\section{Discussion}

Despite the fact that human chromosomal Q-HRs has been studied for more than forty years, their biological role and nature remain unclear. A remarkable feature of human chromosomal Q-HRs is their wide quantitative variability characterized by the fact that individuals in a population differ in the number, location, size and intensity of fluorescence of these specific fluorescent areas (Paris Conference, 1971, 1975). The existence of population Q-HRs variability in twelve polymorphic loci of seven autosomes is a well-established fact (Lubs et al., 1977; Al-Nassar et al., 1981; Ibraimov \& Mirrakhimov, 1982a, 1982b, 1982c; Ibraimov et al., 1982, 1986, 1990, 1991, 2000, 2013; Kalz et al., 2005).

We have studied over 20 human populations of Eurasia and Africa, representing all the three major racial groups. These studies showed that certain human populations differ considerably from each other and these differences are mainly related to the environment they live in and not to racial or ethnic features. In particular, the mean number of Q-HRs per individual is considerably lower in the genome of populations living permanently in the North and at high altitude, as well as in newcomers well adapted to extreme environmental conditions of high altitudes (mountaineers) and the Far North (borers - oil industry workers of West Siberia), as compared to populations living in temperate zones of Eurasia and in low-altitude subequatorial Africa (Ibraimov \& Mirrakhimov, 1982a, 1982b, 1982c; Ibraimov et al., 1982, 1986, 1990, 1991, 2000, 2013).

Based on these observations, we have at one time put forward the hypothesis on the possible selective value of chromosomal Q-HRs in the adaptation of human populations to certain extreme environmental factors - in particular to cold and hypoxia. These same data are the basis of our cytogenetic model of the origin of contemporary man. We feel that a conclusive role in this unique process could be played by features of the chromosomal Q-HR system, only inherent to our nearest ancestors and inherited by us, and not by the 
appearance of new specific structural genes or gene complexes (Ibraimov, 1993, 2010, 2011; Ibraimov et al., 1986).

If our assumption on the possible selective value of the amount of chromosomal Q-HRs in human adaptation and the origin of man is correct, than validation of this hypothesis requires, among other things, further reliable data on the amount of Q-HRs in the genome of individuals from different age groups, because we have sufficient reasons to believe that individuals with a lesser amount of Q-HRs in their genome are not only able to adapt themselves better to certain extreme environmental factors, but also have more chances to live to old age (Ibraimov \& Karagulova, 2006a, 2006b).

In the literature we have found only two studies directly or indirectly devoted to chromosomal Q-HR variability in individuals from different age groups. Thus, Buckton et al. (1976) have examined three Scottish populations. Two of the populations, newborn babies and 14 year old cohort, were from the Scottish mainland (Edinburgh area). The third population (65 years and over) was from Barra, a relatively isolated island in the Outer Hebrides. The authors came to the conclusion that "rather more variation is found in the Q-band intensity polymorphisms: the island population appears to have fewer Brilliant and intense variants than do the other two groups, 2.9 per person as compared to 4.2 and 3.9 for the newborn and 14 years old subjects, respectively; this may be an age differences rather than a population differences". However, the authors remarked that "these figures may reflect a real phenomenon in that the Barra population shows less polymorphic variation than the mainland populations; but equally well they may reflect a possible age difference, perhaps in the way that chromosomes from aged individuals respond to technical treatment? These possibilities could be evaluated by studying Barra and mainland population samples with a vertical age distribution". Unfortunately, as far as we know, such a study has not yet been carried out in either Scotland or elsewhere.

In Siberia, Nazarenko (1987) tried to reveal "age-related changes in the frequency of chromosomal Q-polymorphism in an ethnically homogeneous normal human population". The age of the subjects studied ranged from 7 to 101 years. The author divided them into 3 age groups: 7 to 19 years old, 20 to 29 and 50 years old and over. He found the following changes in the mean number of Q-variants per individual in these 3 age groups: $3.67 \pm 0.10 ; 3.45 \pm 0.14$ and $3.12 \pm 0.18$, respectively.

Two explanations are proposed (Geraedts \& Pearson, 1974; Nazarenko, 1987) for the somewhat decreased mean number of chromosomal Q-HRs in the older individuals as compared to those under 20 years of age who were similar in other respects: (1) Q-HRs instability during ontogenesis; and (2) the dependence of adaptability and survival upon the location of Q-HRs.

The first hypothesis is to be confirmed by continuous follow-up in a large sample of individuals (from the onset of zygote formation to death). As far as we know, such studies have not been performed. The second hypothesis is not confirmed by our data showed that as a rule, increases in the mean number of Q-HRs are accompanied by increases in absolute Q-HR frequencies on all the autosomes, and vice versa. Populations with a low mean number of O-HRs per individual also have a narrow range of variability in the amount of chromosomal Q-HRs (Ibraimov, 1993, 2010, 2011; Ibraimov et al., 2000). This is also documented by data presented here.

Earlier, examining individuals of different age groups, representing two racial-ethnic groups (Kyrgyz and Russians, living in Kyrgyzstan), we confirmed the observations of British and Russian researchers (Ibraimov \& Karagulova, 2006a). The reasons for returning to this problem were as following: a) the above quotes of British researchers imply that the authors were not sure of their findings because of their choice of older people, who were from the island of Barra, whereas the newborn and 14 years old subjects were taken from mainland Scotland (Buckton et al., 1976); b) differences in the mean number of Q-HRs on the individual in the population between the three age groups, obtained in Siberia (Nazarenko, 1987), were not statistically significant; c) in the previous study (Ibraimov \& Karagulova, 2006a, 2006b), we used the data obtained in different years with the help of chemical reagents which were not always of high quality (all produced in the former USSR). In this study, we tried to eliminate all these problems by using high-quality chemical reagents and culture medium (Sigma Chemical Co., USA), and the collection of blood samples was carried out for one year in Almaty. As shown above, our new data have fully confirmed all previous observations on the existence of differences in the number of chromosomal Q-HRs in the genome between individuals of different age groups in the human population.

Thus, the existence of considerable differences in the amount of chromosomal Q-HRs in individuals of different age groups in the population is an established fact. However, there is no agreement as to the nature of Q-HRs variability, although arguments are based on the 'selectionist' hypothesis. One approach, implying that Q-HRs with different locations were basically similar in structural and functional features, were defined by Ibraimov et al. (1986) in the following manner: "of primary importance to an individual is the dose and not the location of 
Q-HR". The term "dose" is defined as the amount of Q-heterochromatin material in the genome regardless of its location in any chromosome. In other words, this approach is based on the assumption that Q-HR lack locus-specificity. Those favoring the alternative approach believe that deviations from expected Q-HR frequencies, observed in any loci, reflect some structural and functional features of these loci and are due either to selection or to nonfortuitous segregation of chromosomes bearing the given Q-HR (Geraedts \& Pearson, 1974; Mikelsaar et al., 1975; Nazarenko et al., 1987).

The hypothesis on which the project is based on assumption that older individuals probably have a lower number of Q-HRs in their genome than younger ones from the same population. If this proves to be true, then we have the right to assume that individuals with a smaller amount of Q-HRs in their genome are not only able to adapt themselves better to certain extreme environmental factors, but also have more chances, other things being equal, to live to old age. And indeed, our data indicate that: 1) in a population there is a clear-cut tendency towards a decrease in the number of chromosomal Q-HRs with age, regardless of racial and ethnic features on the individuals (Tables 1 and 2);2) of all the age groups the genome of neonates contains the greatest amount of Q-HRs; 3) decreases in the number of Q-HRs with age are not due to the "loss" of Q-heterochromatin on individual loci or chromosomes, but occur simultaneously in all the seven Q-polymorphic autosomes (Table 4), in keeping with all our previous observations (Ibraimov, 1993, 2010, 2011; Ibraimov et al., 1986, 1990, 1991, 1997, 2013)

We believe that the decrease in the amount of Q-HRs with age in a population is not an ontogenetic process, but rather the result of natural selection where individuals with a greater number of chromosomal Q-HRs in their genome than on the average in a population "fall out". Therefore, we once again suggest that the cause of the observed differences lies in differential adaptability of individuals with different amounts of Q-heterochromatin material in their genome regardless of its location in any chromosome.

\section{References}

Al-Nassar, K. E., Palmer, C. G., Connealy, P. M., \& Pao-Lo, Y. (1981). The genetic structure of the Kuwaiti population. II. The distribution of Q-band chromosomal heteromorphisms. Hum. Genet., 57, 423-427. http://dx.doi.org/10.1007/BF00282021

Buckton, K. E., O’Riordan, M. L., Jacobs, P. A., Robinson, J. A., Hill, R., \& Evans, H. J. (1976). C- and Q-band polymorphisms in the chromosomes of three human populations. Ann. Hum. Genet., 40, 90-112. http://dx.doi.org/10.1111/j.1469-1809.1976.tb00168.x

Decsey, K., Bellovits, O., \& Bujdoso, G. M. (2006). Human chromosomal polymorphism in a Hungarian sample. Int. J. Hum. Genet., 6(3), 177-183.

Geraedts, J. P. M., \& Pearson, P. L. (1974). Fluorescent chromosome polymorphisms: frequencies and segregation in a Dutch population. Clin. Genet., 6, 247-257. http://dx.doi.org/10.1111/j.1399-0004.1974.tb02086.x

Hungerford, D. A. (1965). Leucocytes cultured from small inocula of whole blood and preparation of metaphase chromosomes by treatment with hypotonic KCl. Stain Technol., 40, 333-338.

Ibraimov, A. I. (1983). Chromosome preparations of human whole lymphocytes - an improved technique. Clin. Genet., 24, 240-242. http://dx.doi.org/10.1111/j.1399-0004.1983.tb00077.x

Ibraimov, A. I. (1993). The origin of modern humans: a cytogenetic model. Hum. Evol., 8(2), 81-91. http://dx.doi.org/10.1007/BF02436607

Ibraimov, A. I. (2010). Chromosomal Q-heterochromatin regions in populations and human adaptation. In M. K. Bhasin \& C. Susanne (Eds.), Anthropology Today: Trends and Scope of Human Biology (pp. 225-250). Delhi: Kamla- Raj Enterprises.

Ibraimov, A. I. (2011). Origin of modern humans: a cytogenetic model. Hum. Evol., 26(1-2), 33-47.

Ibraimov, A. I., Akanov, A. A., Meymanaliev, T. S., Karakushukova, A. S., Kudrina, N. O., Sharipov, K. O., \& Smailova, R. D. (2013). Chromosomal Q-heterochromatin polymorphisms in 3 ethnic groups (Kazakhs, Russians and Uygurs) of Kazakhstan. Int. J. Genet., 5(1), 121-124.

Ibraimov, A. I., \& Karagulova, G. O. (2006a). Chromosomal Q-heterochromatin regions in individuals of various age groups. Int. J. Hum. Genet., 6(3), 219-228.

Ibraimov, A. I., \& Karagulova, G. O. (2006b). Chromosomal Q-heterochromatin variability in neonates deceased during first year of age. Int. J. Hum. Genet., 6(4), 281-285. 
Ibraimov, A. I., \& Mirrakhimov, M. M. (1982a). Human chromosomal polymorphism. III. Chromosomal Q-polymorphism in Mongoloids of northern Asia. Hum. Genet., 62, 252-257. http://dx.doi.org/10.1007/BF00333531

Ibraimov, A. I., \& Mirrakhimov, M. M. (1982b). Human chromosomal polymorphism. IV. Chromosomal Q-polymorphism in Russians living in Kyrghyzia. Hum. Genet., 62, 258-260. http://dx.doi.org/10.1007/BF00333532

Ibraimov, A. I., \& Mirrakhimov, M. M. (1982c). Human chromosomal polymorphism. V. Chromosomal Q-polymorphism in African populations. Hum. Genet., 62, 261-265. http://dx.doi.org/10.1007/BF00333533

Ibraimov, A. I., \& Mirrakhimov, M. M. (1985). Q-band polymorphism in the autosomes and the Y chromosome in human populations. In A. A. Sandberg \& R. Alan (Eds.), Progress and Topics in Cytogenetics. The Y chromosome. Part A. Basic Characteristics of the Y chromosome (pp 213-87). New York: Liss Inc.

Ibraimov, A. I., Axenrod, E. I., Kurmanova, G. U., \& Turapov, O. A. (1991). Chromosomal Q-heterochromatin regions in the indigenous population of the northern part of West Siberia and new migrants. Cytobios, 67, 95-100.

Ibraimov, A. I., Karagulova, G. O., \& Kim, E. Y. (2000). The relationship between the Y chromosome size and the amount of autosomal Q-heterochromatin in human populations. Cytobios, 102, 35-53.

Ibraimov, A. I., Kurmanova, G. U., Ginsburg, E. Kh., Aksenovich, T. I., \& Axenrod, E. I. (1990). Chromosomal Q-heterochromatin regions in native highlanders of Pamir and Tien-Shan and in newcomers. Cytobios, 63, 71-82.

Ibraimov, A. I., Mirrakhimov, M. M., Axenrod, E. I., \& Kurmanova, G. U. (1986). Human chromosomal polymorphism. IX. Further data on the possible selective value of chromosomal Q-heterochromatin material. Hum. Genet., 73, 151-156. http://dx.doi.org/10.1007/BF00291606

Ibraimov, A. I., Mirrakhimov, M. M., Nazarenko, S. A., Axenrod, E. I., \& Akbanova, G. A. (1982). Human chromosomal polymorphism. I. Chromosomal Q-polymorphism in Mongoloid populations of Central Asia. Hum. Genet., 60, 1-7. http://dx.doi.org/10.1007/BF00281254

John, B. (1988). The biology of heterochromatin. In R. S. Verma (Ed.), Heterochromatin: molecular and structural aspects (pp. 1-147). Cambridge University Press.

Kalz, L., Kalz-Fuller, B., Hedge, S., \& Schwanitz, G. (2005). Polymorphism of Q-band heterochromatin; qualitative and quantitative analyses of features in 3 ethnic groups (Europeans, Indians, and Turks). Int. $J$. Hum. Genet., 5(2), 153-163.

Lubs, H. A., Patil, S. R., Kimberling, W. J., Brown, J., Hecht, F., Gerald, P., \& Summitt, R. L. (1977). Racial differences in the frequency of Q- and C-chromosomal heteromorphism. Nature, 268, 631-632. http://dx.doi.org/10.1038/268631a0

Mikelsaar, A. V. N., Kaosaar, M. E., Tuur, S. J., Viikmao, M. H., Talvik, T. A., \& Laats, J. (1975). Human karyotype polymorphism. III. Routine and fluorescence microscopic investigation of chromosomes in normal adults and mentally retarded children. Humangenetik, 26, 1-8.

Müller, H. J., Klinger, H. P., \& Glasser, M. (1975). Chromosome polymorphism in a human newborn population. II. Potentials of polymorphic chromosome variants for characterizing the idiogram of an individual. Cytogenet Cell Genet., 15, 239-255. http://dx.doi.org/10.1159/000130522

Nazarenko, S. A. (1987). Age dynamics of fluorescent polymorphism in human chromosomes. Cytol. Genet. (Russian), 21, 183-186.

Paris Conference and Supplement. (1971, 1975). Standartization in human cytogenetics. Birth Defects, 6, 1-84.

Stanyon, R., Studer, M., Dragone, A., De Benedictis, G., \& Brancati, C. (1988). Population cytogenetics of Albanians in Cosenza (Italy): frequency of Q- and C-band variants. Int. J. Anthropol., 3, 19-29.

Yamada, K., \& Hasegawa, T. (1978). Types and frequencies of Q-variant chromosomes in a Japanese population. Hum. Genet., 44, 89-98. http://dx.doi.org/10.1007/BF00283578 


\section{Copyrights}

Copyright for this article is retained by the author(s), with first publication rights granted to the journal.

This is an open-access article distributed under the terms and conditions of the Creative Commons Attribution license (http://creativecommons.org/licenses/by/3.0/). 